Research Article

\title{
Mesoporous Magnesium Oxide Adsorbent Prepared via Lime (Citrus aurantifolia) Peel Bio-templating for $\mathrm{CO}_{2}$ Capture
}

\author{
A.H. Ruhaimi1 ${ }^{1}$ C.C. Teh¹, Muhammad Arif A. Azizi,2,*) \\ ${ }^{1}$ School of Chemical and Energy Engineering, Faculty of Engineering, Universiti Teknologi Malaysia \\ (UTM), 81310 UTM Johor Bahru, Johor, Malaysia. \\ ${ }^{2}$ Centre of Hydrogen Energy, Institute of Future Energy, Universiti Teknologi Malaysia (UTM), 81310 \\ UTM Johor Bahru, Johor, Malaysia.
}

Received: $2^{\text {nd }}$ March 2021; Revised: 11 th April 2021; Accepted: $12^{\text {th }}$ April 2021

Available online: 12 $2^{\text {nd }}$ April 2021; Published regularly: June 2021

\section{Abstract}

The utilization of the lime (Citrus aurantifolia) peel as a template can improve the adsorbent's structural properties, which consequently affect its $\mathrm{CO}_{2}$ uptake capacity. Herein, a mesoporous magnesium oxide (MgO-lime (Citrus aurantifolia) peel template (LPT)) adsorbent was synthesized using an LPT. MgO-LPT demonstrated improved structural properties and excellent $\mathrm{CO}_{2}$ uptake capacity. Moreover, another $\mathrm{MgO}$ adsorbent was prepared via thermal decomposition (MgO-TD) for comparison. The prepared adsorbents were characterized by $\mathrm{N}_{2}$ physisorption, Fourier transform infrared spectroscopy and thermogravimetric analysis. The $\mathrm{CO}_{2}$ uptake of these adsorbents was under $100 \% \mathrm{CO}_{2}$ gas and ambient temperature and pressure conditions. MgO-LPT exhibited a higher BrunauerEmmett-Teller surface area, Barrett-Joyner-Halenda pore volume, and pore diameter of $23 \mathrm{~m}^{2} \cdot \mathrm{g}^{-1}, 0.142 \mathrm{~cm}^{3} \cdot \mathrm{g}^{-1}$, and $24.6 \mathrm{~nm}$, respectively, than those of $\mathrm{MgO}-\mathrm{TD}$, which indicated the mesoporous structure of $\mathrm{MgO}-\mathrm{LPT}$. The $\mathrm{CO}_{2}$ uptake capacity of $\mathrm{MgO}$-LPT is $3.79 \mathrm{mmol} \mathrm{CO} 2 \mathrm{~g}^{-1}$, which is 15 times that of MgO-TD. This study shows that the application of lime peel as a template for the synthesis of $\mathrm{MgO}$ adsorbents is a promising approach to achieve $\mathrm{MgO}$ adsorbents with enhanced surface area and thus increased $\mathrm{CO}_{2}$ capture performance.

Copyright (C) 2021 by Authors, Published by BCREC Group. This is an open access article under the CC BY-SA License (https://creativecommons.org/licenses/by-sa/4.0).

Keywords: bio-templating; $\mathrm{CO}_{2}$ capture; Citrus aurantifolia; lime peel template; magnesium oxide

How to Cite: A.H. Ruhaimi, C.C. Teh, M.A.A. Aziz (2021). Mesoporous Magnesium Oxide Adsorbent Prepared via Lime (Citrus aurantifolia) Peel Bio-templating for $\mathrm{CO}_{2}$ Capture. Bulletin of Chemical Reaction Engineering \& Catalysis, 16(2), 366-373 (doi:10.9767/bcrec.16.2.10505.366-373)

Permalink/DOI: https://doi.org/10.9767/bcrec.16.2.10505.366-373

\section{Introduction}

Conventional $\mathrm{CO}_{2}$ separation methods (such as amine absorption) have several limitations, including high equipment corrosion rate, high regeneration cost, loss of solvent and low $\mathrm{CO}_{2}$ loading capacity; thus, replacement of these methods with other $\mathrm{CO}_{2}$ capture techniques

* Corresponding Author.

Email: m.arif@utm.my (M.A.A. Aziz) should be considered [1]. In this regard, one of the potential replacement methods is adsorption, which has been reported to possess promising advantages, for example, durability, easy regeneration, cost-effectiveness, and high adsorption capacity of the adsorbents [2,3]. Various adsorbents, such as zeolites, metal oxides, porous carbon, silica, metal-organic frameworks and covalent organic frameworks can be employed to achieve adsorption [4]. Each adsorbent possesses unique tuneable morphological and textural 
properties, which have been extensively studied to realize maximum $\mathrm{CO}_{2}$ uptake capacity. Magnesium oxide $(\mathrm{MgO})$ is a metal oxide adsorbent that has been widely investigated for achieving a high $\mathrm{CO}_{2}$ uptake capacity due to its unique properties including appropriate surface basicity, a high theoretical uptake capacity of $24.8 \mathrm{mmol} \mathrm{CO}_{2} \cdot \mathrm{g}^{-1}$, easy availability and non-toxicity $[5,6]$. However, the low surface area of common $\mathrm{MgO}$ results in a low $\mathrm{CO}_{2}$ uptake capacity. Thus, numerous studies have been conducted to improve the surface area of $\mathrm{MgO}$ for realizing a high theoretical $\mathrm{CO}_{2}$ uptake capacity.

Several fabrication approaches have been reported to improve the surface area of $\mathrm{MgO}$, most of which involve the utilization of a surfactant as a porous generator. The most commonly used surfactant is cetyltrimethylammonium bromide [7,8]. Although various surfactants, such as sodium dodecyl sulfate, polyvinyl pyrrolidone, symmetric triblock copolymer (P123), and cetyltrimethylammonium chloride have been used to achieve high-surface-area adsorbents surfactant-utilizing methods are costly and complex $[1,9]$. Hence, the utilization of biomaterials as template sources for the fabrication of high-surface-area adsorbents can be a promising approach because biomaterials are abundantly available. Furthermore, biomaterial templating requires minimal reagents, thereby reducing the adsorbent preparation cost.

Many studies have reported the use of biomaterials, for instance, jute fibers, root hair, scallion root, and eggshell membranes [1] as templates to improve the physicochemical properties of metal oxide samples and consequently enhance the performances of these samples. For instances, Chen et al. has reported on the fabrication of the $\mathrm{CuO}$ via utilization plant root hair as a template [10]. Fabricated root hairtemplated $\mathrm{CuO}$ has exhibited unique morphological features of the double hollow layer structure, which has resulted in the improvement of gas sensing performance. Moreover, Abarna et al. also reported on the utilization of plant-based material as a template which is jute fibre in the preparation of mesoporous $\mathrm{ZnO}$ [9]. It is found that jute fiber-templated $\mathrm{ZnO}$ has displayed an improvement of structural properties as compared to $\mathrm{ZnO}$ prepared without jute fiber. This enhanced $\mathrm{ZnO}$ 's structural properties have contributed to the high $\mathrm{ZnO}$ photocatalytic efficiency. There are tremendous sources of bio-material that could be used as a template in synthesizing metal oxide adsorbent such as fruit peel waste. However, the use of fruit peel waste, such as: citrus peel as a potential biomaterial template, has rarely been reported to date.

Various citrus species fruit peel can be used as templates. Each species may possess different morphological features. For example, although orange (Citrus sinensis) peel, citrus (Citrus limetta) peel, and lemon (Citrus limon) peel exhibit the same rough surface morphological features with numerous porous structures but their pore sizes are different. Another unique morphological feature of orange peel is that some fibrous structures are spread throughout its surface [11]. Moreover, citrus peel possesses several surface functional groups, including carboxyl, alcohol, aldehyde, ketone, alkene, amide, ester, and ether groups [11]. Thus, utilization of citrus fruit peel with interesting morphological characteristic as a template in synthesizing $\mathrm{MgO}$ is beneficial toward adsorbent physicochemical properties and further expected leading to the improvement of adsorbent's $\mathrm{CO}_{2}$ capture performance.

In this study, the lime (Citrus aurantifolia) peel template was utilized as a template in the preparation of mesoporous $\mathrm{MgO}$ adsorbent (MgO-LPT). The prepared adsorbents were characterized using $\mathrm{N}_{2}$ physisorption, Fourier transform infrared spectroscopy (FTIR), and thermogravimetric analysis (TGA). The $\mathrm{CO}_{2}$ uptake capacities of the adsorbents were investigated under pure $\mathrm{CO}_{2}$ and ambient pressure and temperature conditions.

\section{Materials and Methods}

\subsection{Materials}

All chemical reagents, such as magnesium nitrate hexahydrate $\left(\mathrm{Mg}\left(\mathrm{NO}_{3}\right)_{2} \cdot 6 \mathrm{H}_{2} \mathrm{O}\right)(99.5 \%)$, ethylene glycol $\left(\mathrm{C}_{2} \mathrm{H}_{6} \mathrm{O}_{2}\right)(99.5 \%)$, and ammonia solution $28 \%\left(\mathrm{NH}_{3}\right)$, used in this study were purchased from QREC (Asia) SDN BHD. Lime peel was obtained from the local market.

\subsection{Preparation of MgO-LPT}

LPT was acquired from lime waste and washed three times to remove impurities. The LPT was then dried overnight at $110{ }^{\circ} \mathrm{C}$ and roughly crushed to reduce the template size to approximately less than $0.5 \mathrm{~mm} \times 0.5 \mathrm{~mm}$. Templating was initiated by weighing $20 \mathrm{~g}$ of $\mathrm{Mg}\left(\mathrm{NO}_{3}\right)_{2} \cdot 6 \mathrm{H}_{2} \mathrm{O}$ and then adding it to $200 \mathrm{~mL}$ $\mathrm{C}_{2} \mathrm{H}_{6} \mathrm{O}_{2}$. Subsequently, the mixture was stirred for $10 \mathrm{~min}$ and sonicated for $10 \mathrm{~min}$ to ensure the complete dissolution of $\mathrm{Mg}\left(\mathrm{NO}_{3}\right)_{2} \cdot 6 \mathrm{H}_{2} \mathrm{O}$. Thereafter, $3 \mathrm{~g}$ dried LPT was immersed in the abovementioned solution and stirred for $1 \mathrm{~h}$. 
The $\mathrm{pH}$ of the mixture was set to 10 using $\mathrm{NH}_{3}$, and the resulting mixture was stirred for another $30 \mathrm{~min}$. The MgO-absorbed LPT was then filtered and dried for $1 \mathrm{~h}$ at $110^{\circ} \mathrm{C}$. Next, the dried $\mathrm{MgO}$-absorbed LPT was calcined at 600 ${ }^{\circ} \mathrm{C}$ for $4 \mathrm{~h}$ and ground to achieve powdered MgO-LPT.

\subsection{Preparation of $\mathrm{MgO}-\mathrm{TD}$}

$\mathrm{Mg}\left(\mathrm{NO}_{3}\right)_{2} \cdot 6 \mathrm{H}_{2} \mathrm{O}(20 \mathrm{~g})$ was directly calcined at $600{ }^{\circ} \mathrm{C}$ for $3 \mathrm{~h}$, and then, the calcined residue was ground to obtain powdered $\mathrm{MgO}-\mathrm{TD}$.

\subsection{Characterization}

Surface functional groups of the prepared adsorbents were determined by FTIR using a Cary 600 series spectrometer in the midinfrared range of $400-4000 \mathrm{~cm}^{-1}$. The thermal decomposition behavior of the prepared adsorbents was evaluated via TGA in the temperature range of $30-900{ }^{\circ} \mathrm{C}$ at a scan rate of $10^{\circ} \mathrm{C}$ min $^{-1}$ using PerkinElmer STA 8000. $\mathrm{N}_{2}$ adsorption-desorption isotherms were acquired using a gas sorption analyzer (Quantachrome Instruments, Autosorb IQ, version 3.0) to investigate the textural properties of the adsorbents, and the data were analyzed using the 3Flex 5.0 software.

\subsection{Measurement of $\mathrm{CO}_{2}$ Adsorption}

$\mathrm{CO}_{2}$ adsorption was measured using a fixedbed U-shaped adsorption column equipped with a $\mathrm{CO}_{2}$ analyzer (Quantek Instruments Model 906). The schematic diagram of the $\mathrm{CO}_{2}$ adsorption testing setup was shown in Figure 1. Before adsorption, the adsorbent (50 mg) was pre-treated at $150{ }^{\circ} \mathrm{C}$ for $1 \mathrm{~h}$ under nitrogen flow $\left(20 \mathrm{~mL} \cdot \mathrm{min}^{-1}\right)$ to remove any pre-adsorbed atmospheric gases. Next, the adsorption testing was conducted on pre-treated adsorbent under

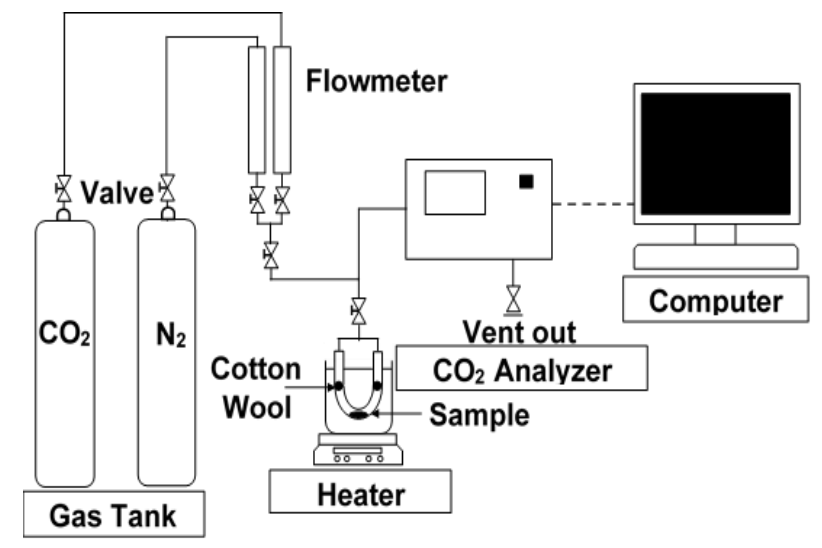

Figure 1. Schematic diagram of $\mathrm{CO}_{2}$ adsorption testing setup. pure $\mathrm{CO}_{2}$ condition at ambient pressure and temperature for $1 \mathrm{~h}$. Subsequently, the adsorbent was desorbed under nitrogen flow (20 mL.min ${ }^{-1}$ ) at $150{ }^{\circ} \mathrm{C}$ for $30 \mathrm{~min}$. $\mathrm{CO}_{2}$ desorbed from the adsorbent was quantified using the area under the adsorption-desorption curve. The $\mathrm{CO}_{2}$ uptake capacity of the adsorbents was calculated using the mean of the results of three adsorption-desorption cycles.

\section{Results and Discussions}

\subsection{Characterization}

FTIR spectra of the prepared adsorbents were recorded in the wavelength range of 400$4000 \mathrm{~cm}^{-1}$. As shown in Figure 2, the spectrum of MgO-LPT exhibits several intense absorption peaks as compared to that of $\mathrm{MgO}$-TD. The sharp absorption peak at $3690 \mathrm{~cm}^{-1}$ and broad vibration band at $3440-3450 \mathrm{~cm}^{-1}$ are attributed to the stretching vibration of the hydroxyl $(-\mathrm{OH})$ group on the crystal face of the lowcoordination site or defect site and residual water, respectively [12,13]. This indicates that $\mathrm{MgO}-\mathrm{LPT}$ possesses more $\mathrm{OH}$ groups than those of MgO-TD, which can lead to the formation of a large amount of bicarbonate on MgO-LPT. The spectra of both adsorbents show a peak at $2370 \mathrm{~cm}^{-1}$, which is associated with the existence of a $\mathrm{CO}_{2}$ molecule [14]. Compared to the case of $\mathrm{MgO}-\mathrm{TD}$, the intensity of the $2370 \mathrm{~cm}^{-1}$ peak of MgO-LPT decreased because of the use of high-intensity incident light due to the high bond population of MgO-LPT [15]. Moreover, the spectrum of MgO-LPT demonstrates more prominent peaks associated with the adsorbed atmospheric $\mathrm{CO}_{2}$ than that of MgO-TD. These peaks are located at $870 \mathrm{~cm}^{-1}$, $1050 \mathrm{~cm}^{-1}$ and $1430-1450 \mathrm{~cm}^{-1}$, and $1655 \mathrm{~cm}^{-1}$, which are assigned to the existence of monodentate carbonate, bicarbonate, and bidentate

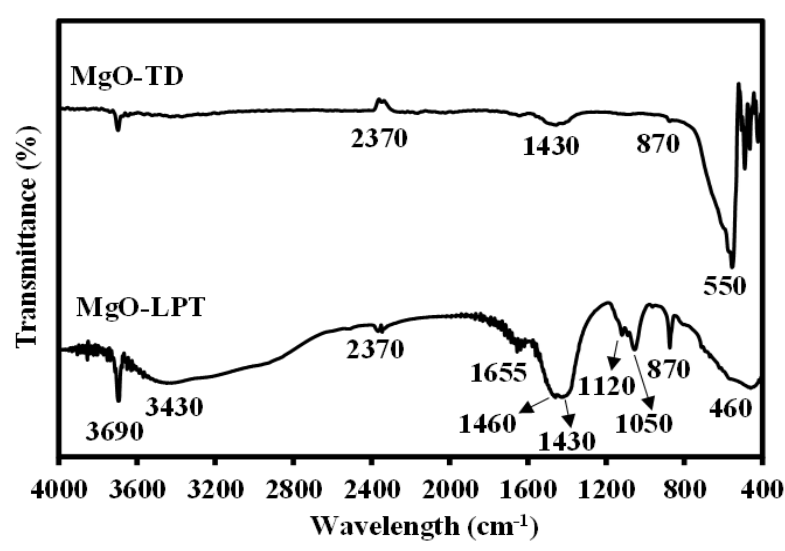

Figure 2. FTIR spectra of $\mathrm{MgO}-\mathrm{TD}$ and $\mathrm{MgO}$ LPT. 
carbonate, respectively [12,16-18]. Furthermore, the band at $1120 \mathrm{~cm}^{-1}$ was attributed to the $v_{1}$ symmetric stretching vibration of $\mathrm{CO}_{3}{ }^{2-}$ [19]. The more intense peaks corresponding to carbonate species in the spectrum of MgO-LPT suggest that $\mathrm{MgO}-\mathrm{LPT}$ possesses more active sites, leading to high $\mathrm{CO}_{2}$ uptake capacity. The sharp peak at $550 \mathrm{~cm}^{-1}$ observed for MgO-TD and the strong peak at $460 \mathrm{~cm}^{-1}$ obtained for MgO-LPT corresponds to the stretching vibration of $\mathrm{Mg}-\mathrm{O}[20,21]$.

As shown in Figure 3(a and b), MgO-TD and $\mathrm{MgO}-\mathrm{LPT}$ demonstrate different decomposition behaviors. This might be owing to the different chemical compositions of the chemical reagents and templates used during the preparation of these adsorbents. Both adsorbents exhibited initial weight loss at $<200{ }^{\circ} \mathrm{C}$, corresponding to the removal of residual moisture; this indicated

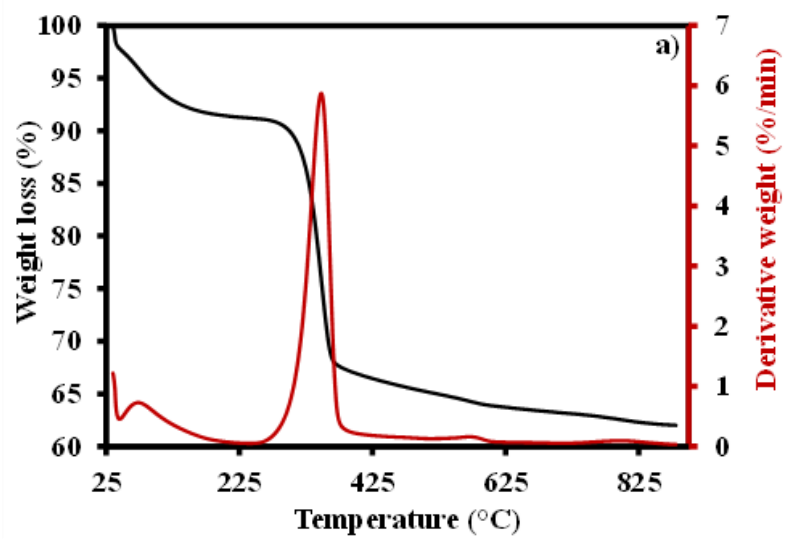

that $\mathrm{MgO}$-LPT had a higher residual moisture content than that of MgO-TD. During the second degradation stage $\left(250-600{ }^{\circ} \mathrm{C}\right), \mathrm{MgO}-\mathrm{TD}$ showed a higher weight loss of $27 \mathrm{wt} \%$ as compared to that of MgO-LPT (only approximately $9 \mathrm{wt} \%$ ) (Table 1). This might imply that $\mathrm{MgO}$ TD possesses more organic residues than those of MgO-LPT. During the third stage of degradation, MgO-LPT exhibited more weight loss than that of MgO-TD, probably because of the removal of carbon residue, also known as fixed carbon, from the template. As MgO-LPT was prepared at $600{ }^{\circ} \mathrm{C}$, a small amount of fixed carbon was still present in it as fixed carbon remains stable at high temperatures $\left(700{ }^{\circ} \mathrm{C}\right)$ [11].

$\mathrm{N}_{2}$ adsorption-desorption measurements were carried out to investigate the structural properties of the adsorbents. Figure $4(\mathrm{a}$ and $\mathrm{b})$

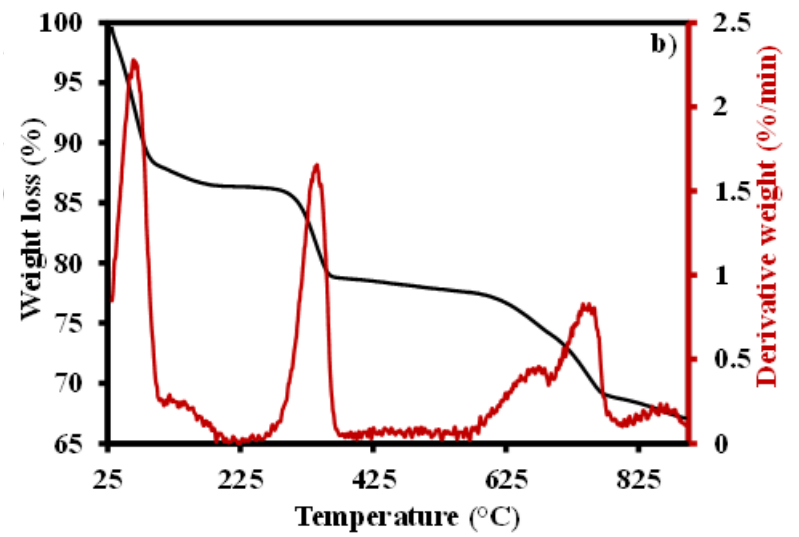

Figure 3. TGA/DTG curve of a) MgO-TD and b) MgO-LPT.
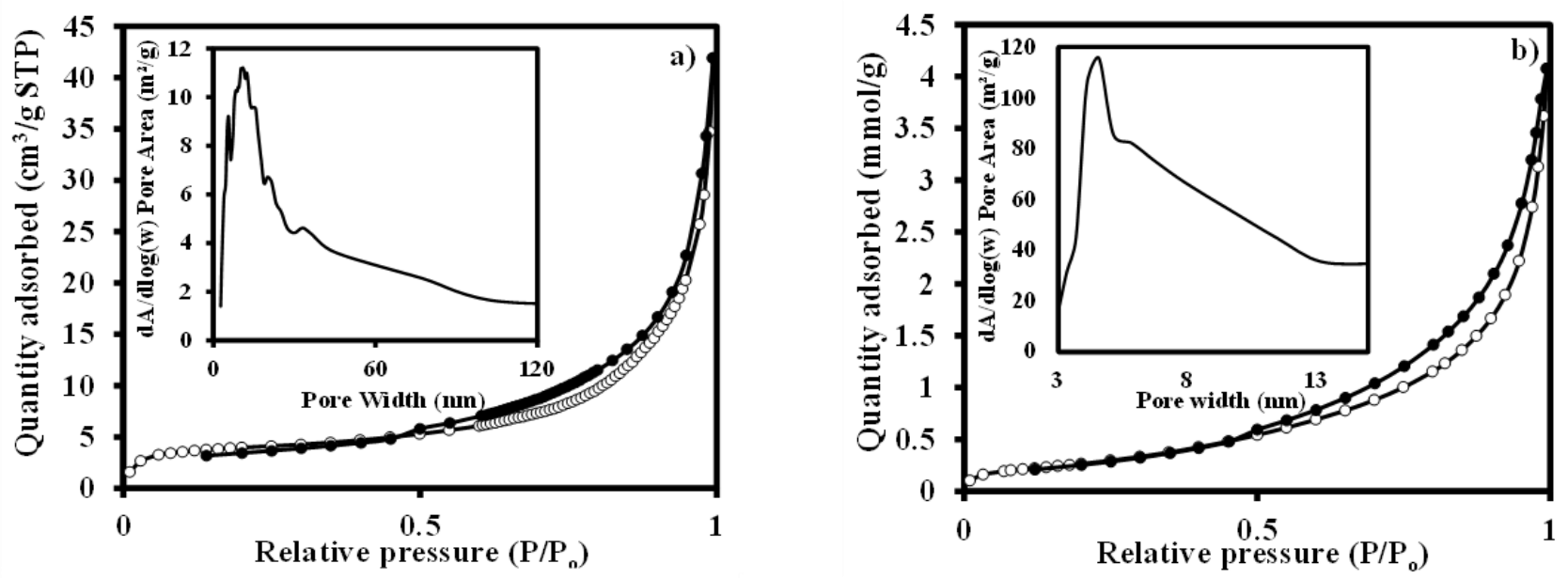

Figure 4. $\mathrm{N}_{2}$ adsorption-desorption isotherm of a) MgO-TD and b) MgO-LPT.

Table 1. Summary of the thermal decomposition behaviors of MgO-TD and MgO-LPT.

\begin{tabular}{ccccc}
\hline \multirow{2}{*}{ Adsorbent } & \multicolumn{3}{c}{ Weight loss (wt\%) } & \multirow{2}{*}{$\begin{array}{c}\text { Total weight loss } \\
\text { (wt\%) }\end{array}$} \\
\cline { 2 - 4 } MgO-TD & $<200{ }^{\circ} \mathrm{C}$ & $-600{ }^{\circ} \mathrm{C}$ & $>600{ }^{\circ} \mathrm{C}$ & 38 \\
MgO-LPT & 9 & 27 & 2 & 34 \\
\hline
\end{tabular}


show that both adsorbents exhibit type IV isotherms with H3 hysteresis loops. This implies that the adsorbents mainly contain mesopores, and the pores are mostly disordered slit pores resulting from the stacking of sheets or particles [22]. The hysteresis loops of the isotherms of both adsorbents were observed in the $\mathrm{P} / \mathrm{P}_{\mathrm{o}}$ range of $0.45-1.0$. Due to the LPT, the specific surface area of $\mathrm{MgO}-\mathrm{LPT}$ increased $\left(23 \mathrm{~m}^{2} . \mathrm{g}^{-1}\right)$ as compared to that of $\mathrm{MgO}-\mathrm{TD}$ (only 13 $\left.\mathrm{m}^{2} \cdot \mathrm{g}^{-1}\right)$. Moreover, the Barrett - Joyner Halenda pore volume and pore diameter of

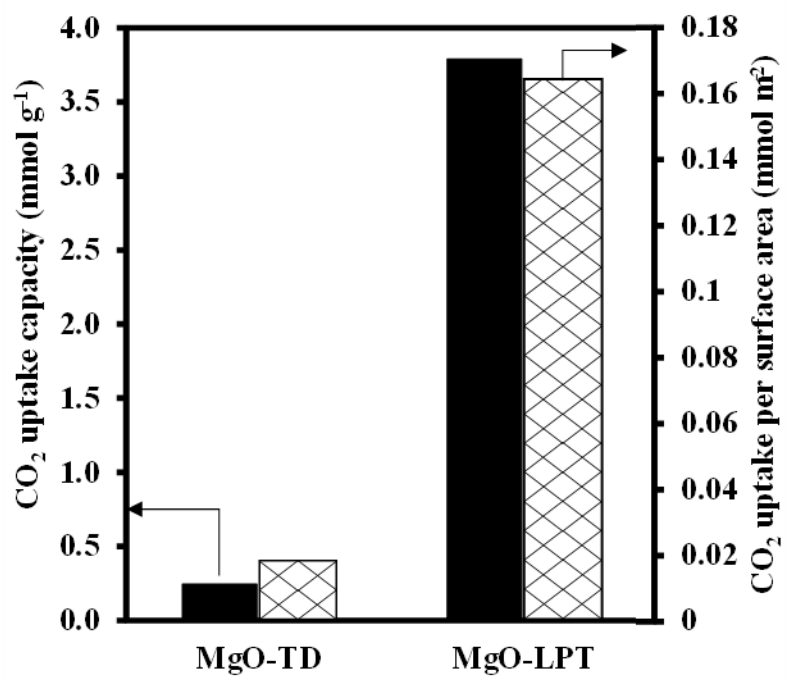

Figure 5. $\mathrm{CO}_{2}$ uptake capacity of $\mathrm{MgO}-\mathrm{TD}$ and MgO-LPT.
$\mathrm{MgO}-\mathrm{LPT}$ increased as compared to those of MgO-TD (Table 2). Thus, the LPT biotemplating improved the structural properties of MgO-LPT and thereby led to the high $\mathrm{CO}_{2}$ uptake capacity of MgO-LPT. This surface area enhancement resulted from the utilization of citrus fruit peel as a template also observed in several studies reported [23,24]. For instances, Zhao et al. has reported in the synthesizing of the hierarchically porous $\mathrm{LaFeO}_{3}$ sample from the pomelo peel as a template [23]. It is found that the $\mathrm{LaFeO}_{3}$ sample exhibited enhanced textural properties than the $\mathrm{LaFeO}_{3}$ sample prepared without pomelo peel as a template. Thus, this enhanced textural property has resulted in better catalytic performance than another prepared sample. This revealed that the utilization of bio-material such as citrus fruit species as a template could improve the adsorbent's structural properties, which consequently influence its performance.

\section{$3.2 \mathrm{CO}_{2}$ Uptake Capacity}

$\mathrm{CO}_{2}$ uptake capacity was examined under $\mathrm{CO}_{2}$ gas and ambient conditions to evaluate the relationship between the structural properties and uptake performance. As shown in Figure 5, MgO-LPT demonstrated a $\mathrm{CO}_{2}$ uptake capacity of $3.79 \mathrm{mmol} \mathrm{CO} 2 . \mathrm{g}^{-1}$, which was 15 times that of $\mathrm{MgO}-\mathrm{TD}$. This was attributed to the enhanced surface area of MgO-LPT. The

Table 2. Textural properties of MgO-TD and MgO-LPT.

\begin{tabular}{lccc}
\hline Adsorbent & Surface area $\left(\mathrm{m}^{2} \cdot \mathrm{g}^{-1}\right)$ & Pore volume $\left(\mathrm{cm}^{3} \cdot \mathrm{g}^{-1}\right)$ & Pore diameter $(\mathrm{nm})$ \\
\hline $\mathrm{MgO}-\mathrm{TD}$ & 13 & 0.065 & 19 \\
$\mathrm{MgO}-\mathrm{LPT}$ & 23 & 0.142 & 25 \\
\hline
\end{tabular}

Table 3. Textural properties and $\mathrm{CO}_{2}$ uptake capacities of the $\mathrm{MgO}$ adsorbents fabricated by various methods.

\begin{tabular}{|c|c|c|c|c|c|c|}
\hline Adsorbent & Synthesis method & $\begin{array}{c}\text { Surface } \\
\text { area } \\
\left(\mathrm{m}^{2} \cdot \mathrm{g}^{-1}\right) \\
\end{array}$ & $\begin{array}{l}\text { Pore volume } \\
\left(\mathrm{cm}^{3} \cdot \mathrm{g}^{-1}\right)\end{array}$ & $\begin{array}{c}\text { Adsorption } \\
\text { temperature } \\
\left({ }^{\circ} \mathrm{C}\right) \\
\end{array}$ & $\begin{array}{l}\mathrm{CO}_{2} \text { uptake } \\
\left(\mathrm{mmol} \cdot \mathrm{g}^{-1}\right)\end{array}$ & Ref. \\
\hline $\mathrm{MgO}-\mathrm{TD}$ & $\begin{array}{l}\text { Thermal decom- } \\
\text { position method }\end{array}$ & 13 & 0.065 & 298 & 0.247 & This work \\
\hline MgO-LPT & $\begin{array}{l}\text { Lime peel biotem- } \\
\text { plating }\end{array}$ & 23 & 0.142 & 298 & 3.79 & This work \\
\hline $\mathrm{MgO}$ & Double-replicate & 250 & 0.53 & 298 & 1.82 & {$[28]$} \\
\hline $\mathrm{MgO}$ & $\begin{array}{l}\text { Precipitation } \\
\text { method }\end{array}$ & 331 & 0.575 & 298 & 1.56 & [29] \\
\hline $\mathrm{MgO}$ & Aerogel method & 686 & 2.11 & 303 & 2.34 & [30] \\
\hline MgO-A & Sol-gel method & 350 & 0.414 & 303 & 0.681 & {$[31]$} \\
\hline $\mathrm{MgO}-\mathrm{O}$ & Sol-gel method & 149 & 0.598 & 303 & 0.568 & [31] \\
\hline $\mathrm{MgO}-\mathrm{N}$ & Sol-gel method & 124 & 0.546 & 303 & 0.545 & {$[31]$} \\
\hline
\end{tabular}


increased surface area of an adsorbent can cause the exposure of more active sites, thus promoting the attachment of more $\mathrm{CO}_{2}[1,25]$. This correlation between enhanced adsorbent's surface area and $\mathrm{CO}_{2}$ uptake capacity also observed in several studies reported. For instances, Guo et al. has successfully fabricated $\mathrm{MgO}$ adsorbents through different preparation method [22]. It is found that each preparation method has resulted in different morphological features. The $\mathrm{MgO}$ adsorbent prepared via solidstate chemical reaction (MgO-SR) has exhibited a sheet-like with higher surface area compared to other prepared samples, which consequently increase the adsorbent's surface-active site. This MgO-SR's structural properties enhancement has contributed to the higher $\mathrm{CO}_{2}$ uptake capacity than those of prepared $\mathrm{MgO}$ adsorbent.

In addition, although MgO-LPT has the smallest surface area than those of the other $\mathrm{MgO}$ adsorbents reported in the literature (Table 3), it still exhibits the highest $\mathrm{CO}_{2}$ uptake capacity per surface area $(0.165$ mmol. $\mathrm{m}^{-2}$ ) as compared to those of the other $\mathrm{MgO}$ adsorbents. This may be because of the presence of rich surface defects on MgO-LPT. This LPT bio-templating might contribute to the generation of point defects such as cationic vacancies and low-coordination anionic sites. The corner, step, and edge sites are the lowcoordination anionic sites of $\mathrm{MgO}$, which are highly polarizable [26] and exhibit high Lewis basicity. The Lewis basicity is the ability of the adsorbent surface to donate an electron pair to the $\mathrm{CO}_{2}$ (Lewis acid) molecule and form a carbonate species [27]. This supported the FTIR results, that is, the spectrum of $\mathrm{MgO}-\mathrm{LPT}$ exhibited more bands corresponding to the carbonate species than those of MgO-TD. It can be concluded that MgO-LPT possesses higher surface reactivity, which results in the easy adsorption of atmospheric $\mathrm{CO}_{2}$, than that of $\mathrm{MgO}$ TD.

\section{Conclusions}

In this study, mesoporous MgO-LPT was successfully fabricated using the LPT as a template. The utilization of LPT has demonstrated the enhancement of adsorbent's structural properties, which MgO-LPT exhibited a higher specific surface area and pore volume as compared to MgO-TD. The improved MgO-LPT surface area has contributed to the high $\mathrm{CO}_{2}$ uptake capacity of $3.79 \mathrm{mmol} \mathrm{CO}_{2} \cdot \mathrm{g}^{-1}$, which is 15-times that of $\mathrm{MgO}$-TD. In addition, even though the surface area of MgO-LPT is the smallest as compared to those of several previously reported $\mathrm{MgO}$ adsorbents, the $\mathrm{CO}_{2}$ uptake capacity of MgO-LPT was the highest than those of the other $\mathrm{MgO}$ adsorbents. Therefore, this study reveals that lime (Citrus aurantifolia) peel is a promising, inexpensive template source for the synthesis of mesoporous $\mathrm{MgO}$ with high $\mathrm{CO}_{2}$ uptake capacity.

\section{Acknowledgements}

This work was supported by the Universiti Teknologi Malaysia (Grant No. 16J64) and Ministry of Higher Education Malaysia through the Fundamental Research Grant $\mathrm{Scheme}$ (FRGS) Grant No. FRGS/1/2019/STG07/UTM/02/8 (Grant No. 5F217).

\section{References}

[1] Ruhaimi, A.H., Aziz, M.A.A., Jalil, A.A. (2021). Magnesium oxide-based adsorbents for carbon dioxide capture: Current progress and future opportunities. Journal of $\mathrm{CO}_{2} \mathrm{Uti}$ lization, 43, 101357 . D O I: 10.1016/j.jcou.2020.101357

[2] Modak, A., Jana, S. (2019). Advancement in porous adsorbents for post-combustion $\mathrm{CO}_{2}$ capture. Microporous and Mesoporous Materials, $276, \quad 107-132$. D O I : 10.1016/j.micromeso.2018.09.018

[3] Songolzadeh, M., Ravanchi, M.T., Soleimani, M. (2012). Carbon Dioxide Capture and Storage: A General Review on Adsorbents. International Journal of Chemical and Molecular Engineering, 6(10), 900-907. DOI: 10.5281/zenodo. 1076266

[4] Azmi, A.A., Ruhaimi, A.H., Aziz, M.A.A. $\left(\begin{array}{llll}2 & 0 & 2 & 0\end{array}\right)$. E f f i c i e $\mathrm{n} \mathrm{t} 3$ aminopropyltrimethoxysilane functionalised mesoporous ceria nanoparticles for $\mathrm{CO}_{2}$ capture. Materials Today Chemistry, 16, 100273. DOI: 10.1016/j.mtchem.2020.100273

[5] Hu, Y., Guo, Y., Sun, J., Li, H., Liu, W. (2019). Progress in $\mathrm{MgO}$ sorbents for cyclic $\mathrm{CO}_{2}$ capture: a comprehensive review. Journal of Materials Chemistry A, 7(35), 2010320120. DOI: 10.1039/C9TA06930E

[6] Gao, W., Zhou, T., Gao, Y., Louis, B., O'Hare, D., Wang, Q. (2017). Molten salts-modified $\mathrm{MgO}$-based adsorbents for intermediatetemperature $\mathrm{CO}_{2}$ capture: A review. Journal of Energy Chemistry, 26(5), 830-838. DOI: 10.1016/j.jechem.2017.06.005

[7] Azmi, A.A., Ngadi, N., Kamaruddin, M.J., Zakaria Z.Y., Teh, L.P., Rozali Annuar, N.H., Setiabudi, H.D., Ab Aziz, M.A. (2019). Rapid one pot synthesis of mesoporous ceria nano- 
particles by sol-gel method for enhanced $\mathrm{CO}_{2}$ capture. Chemical Engineering Transactions, 72, 403-408. DOI: 10.3303/CET1972068

[8] Wang, J., Li, M., Lu, P., Ning, P., Wang, Q. (2019). Kinetic study of $\mathrm{CO}_{2}$ capture on ternary nitrates modified $\mathrm{MgO}$ with different precursor and morphology. Chemical Engineering Journal, 392, 123752. DOI: 10.1016/j.cej.2019.123752

[9] Abarna, B., Preethi, T., Karunanithi, A., Rajarajeswari, G. (2016). Influence of jute template on the surface, optical and photocatalytic properties of sol-gel derived mesoporous zinc oxide. Materials Science in Semiconductor Processing, 56, 243-250. DOI: 10.1016/j.mssp.2016.09.004

[10] Chen, G., Yang, X., Miao, K., Long, M., Deng, W. (2017). Root hairs as biotemplates for fabricating hollow double-layer $\mathrm{CuO}$ microtubes. Materials Letters, 194, 193-196. DOI: 10.1016/j.matlet.2017.02.035

[11] Pathak, P.D., Mandavgane, S.A., Kulkarni, B.D. (2017). Fruit peel waste: characterization and its potential uses. Current Science, $113(3), \quad 444-454$. D O I : 10.18520/CS/V113/I03/444-454.

[12] Selvam, N.C.S., Kumar, R.T., Kennedy, L.J., Vijaya, J.J. (2011). Comparative study of microwave and conventional methods for the preparation and optical properties of novel $\mathrm{MgO}$-micro and nano-structures. Journal of Alloys and Compounds, 509(41), 9809-9815. DOI: 10.1016/j.jallcom.2011.08.032

[13] Jeon, H., Min, Y.J., Ahn, S.H., Hong, S.M., Shin, J.S., Kim, J.H., Lee, KB. (2012). Graft copolymer templated synthesis of mesoporous $\mathrm{MgO} / \mathrm{TiO}_{2}$ mixed oxide nanoparticles and their $\mathrm{CO}_{2}$ adsorption capacities. Colloids and Surfaces A: Physicochemical and Engineering Aspects, $414, \quad 75-81$. D O I : 10.1016/j.colsurfa.2012.08.009

[14] Bazhan, Z., Ghodsi, F.E., Mazloom, J. (2013). Effect of stabilizer on optical and structural properties of $\mathrm{MgO}$ thin films prepared by solgel method. Bulletin of Materials Science, 36(5), 899-905. DOI: 10.1007/s12034-0130554-0

[15] Fuqua, P.D., Mansour, K., Alvarez Jr,D., Marder, S.R., Perry, J.W., Dunn, B.S. (1992). Synthesis and nonlinear optical properties of sol-gel materials containing phthalocyanines. In SPIE Proceedings: Sol-Gel Optics II, 1758. San Diego, CA, United States. DOI: 10.1117/12.132042

[16] Yang, N., Ning, P., Li, K., Wang, J. (2018). $\mathrm{MgO}$-based adsorbent achieved from magnesite for $\mathrm{CO}_{2}$ capture in simulate wet flue gas. Journal of the Taiwan Institute of Chemical Engineers, 86, 73-80. DO I: 10.1016/j.jtice.2018.02.006
[17] Ding, Y.D., Song, G., Liao, Q., Zhu, X., Chen, R. (2016). Bench scale study of $\mathrm{CO}_{2}$ adsorption performance of $\mathrm{MgO}$ in the presence of water vapor. Energy, 112, 101-110. DOI: 10.1016/j.energy.2016.06.064

[18] Kwon, H.K., Park, D.G. (2009). Infra-red study of surface carbonation on polycrystalline magnesium hydroxide. Bulletin of the Korean Chemical Society, 30(11), 2567-2573. DOI: $10.5012 /$ bkcs.2009.30.11.2567

[19] Botha, A., Strydom, C. (2003). DTA and FTIR analysis of the rehydration of basic magnesium carbonate. Journal of Thermal Analysis and Calorimetry, 71(3), 987-996. DOI: 10.1023/A:1023355016208

[20] Li, P., Lin, Y., Chen, R., Li, W. (2020). Construction of a hierarchical-structured $\mathrm{MgO}$ carbon nanocomposite from a metal-organic complex for efficient $\mathrm{CO}_{2}$ capture and organic pollutant removal. Dalton Transactions. DOI: 10.1039/D0DT00722F

[21] Sutapa, I.W., Wahab, A.W., Taba, P., La Nafie, N. (2018). Synthesis and structural profile analysis of the $\mathrm{MgO}$ nanoparticles produced through the sol-gel method followed by annealing process. Oriental Journal of Chemistry, 34(2), 1016. DOI: 10.13005/ojc/340252

[22] Guo, Y., Tan, C., Wang, P., Sun, J., Li, W., Zhao, C., Lu, P. (2020). Structureperformance relationships of magnesiumbased $\mathrm{CO}_{2}$ adsorbents prepared with different methods. Chemical Engineering Journal, 379, 122277. DOI: 10.1016/j.cej.2019.122277

[23] Zhao, S., Wang, L., Wang, Y., Li, X. (2018). Hierarchically porous $\mathrm{LaFeO}_{3}$ perovskite prepared from the pomelo peel bio-template for catalytic oxidation of NO. Journal of Physics and Chemistry of Solids, 116, 43-49. DOI: 10.1016/j.jpcs.2017.12.057

[24] Zhao, R., Zhang, X., Peng, S., Hong, P., Zou, T., Wang, Z., Xing, X., Wang, Y. (2020). Shaddock peels as bio-templates synthesis of $\mathrm{Cd}$ doped $\mathrm{SnO}_{2}$ nanofibers: A high performance formaldehyde sensing material. Journal of Alloys and Compounds, 813, 152170. DOI: 10.1016/j.jallcom.2019.152170

[25] Tian, P., Han, X.Y., Ning, G.L., Fang, H.X., Ye, J.W., Gong, W.T., Lin, Y. (2013). Synthesis of porous hierarchical $\mathrm{MgO}$ and its superb adsorption properties. ACS Applied Materials and Interfaces, 5(23), 12411-12418. DOI: 10.1021/am403352y

[26] Montero, J., Isaacs, M., Lee, A., Lynam, J., Wilson, K. (2016). The surface chemistry of nanocrystalline $\mathrm{MgO}$ catalysts for FAME production: An in situ XPS study of $\mathrm{H}_{2} \mathrm{O}, \mathrm{CH}_{3} \mathrm{OH}$ and $\mathrm{CH}_{3} \mathrm{OAc}$ adsorption. Surface Science, $646, \quad 170-178 . \quad$ D O I : 10.1016/j.susc.2015.07.011 
[27] Cornu, D., Guesmi, H., Krafft, J.M., LauronPernot, H. (2012). Lewis Acido-Basic Interactions between $\mathrm{CO}_{2}$ and $\mathrm{MgO}$ Surface: DFT and DRIFT Approaches. The Journal of Physical Chemistry C, 116(11), 6645-6654. DOI: 10.1021/jp211171t

[28] Bhagiyalakshmi, M., Lee, J.Y., Jang, H.T. (2010). Synthesis of mesoporous magnesium oxide: its application to $\mathrm{CO}_{2}$ chemisorption. International Journal of Greenhouse Gas Control, 4(1), $51-56$. D O I : 10.1016/j.ijggc.2009.08.001

[29] Tuan, V.A., Lee, C.H. (2018). Preparation of rod-like $\mathrm{MgO}$ by simple precipitation method for $\mathrm{CO}_{2}$ capture at ambient temperature. $\mathrm{Vi}$ etnam Journal of Chemistry, 56(2), 197-202. DOI: $10.1002 /$ vjch.201800013
[30] Ho, K., Jin, S., Zhong, M., Vu, A.T., Lee, C.H. (2017). Sorption capacity and stability of mesoporous magnesium oxide in post-combustion $\mathrm{CO}_{2}$ capture. Materials Chemistry and Phys$i c s, \quad 198, \quad 154-161$. D O I : 10.1016/j.matchemphys.2017.06.002

[31] Alkadhem, A.M., Elgzoly, M.AA., Onaizi, S.A. (2020). Novel Amine-Functionalized Magnesium Oxide Adsorbents for $\mathrm{CO}_{2}$ Capture at Ambient Conditions. Journal of Environmental Chemical Engineering, 8(4), 103968. DOI: 10.1016/j.jece.2020.103968

Selected and Revised Papers from International Conference on Sustainable Energy and Catalysis 2021 (ICSEC 2021) (https://engineering.utm.my/chemicalenergy/icsec2021/) (School of Chemical and Energy Engineering, Faculty of Engineering, Universiti Teknologi Malaysia, 16-17th February 2021) after Peer-reviewed by Scientific Committee of ICSEC 2021 and Peer-Reviewers of Bulletin of Chemical Reaction Engineering \& Catalysis.

Editors (Guest) in this ICSEC 2021 section are Nor Aishah Saidina Amin, Mohd Asmadi Mohammed Yussuf, Salman Raza Naqui, while Editor in Chief is I. Istadi. 